\title{
PSYCHOLOGICAL AND DIDACTIC ASPECTS OF THE POSSIBILITY OF USING INTERNET TECHNOLOGIES IN TEACHING EFL
}

\author{
Kudaybergenova Nargiza Konisbayevna ${ }^{1}$, \\ Yeshniyazova Tamara Matenovna ${ }^{2}$

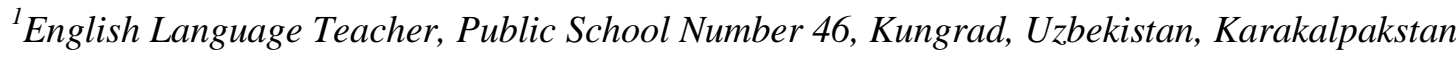 \\ ${ }^{2}$ Foreign Languages Department, Nukus State Pedagogical Institute, Nukus, Uzbekistan, \\ Karakalpakstan
}

Article DOI: https://doi.org/10.36713/epra9290

DOI No: 10.36713/epra9290

\begin{abstract}
The article describes the significance of Internet technologies (IT) in the teaching process of English as a foreign language (EFL) and reviews the researchers' opinions on this problem. In this paper, the author considers that Internet technologies in English lessons for pupils in grades 5-7, it is appropriate to briefly dwell on psychological features of this age. In the article, a number of scientific studies in the field of computerization of learning in foreign languages have been analyzed. The article focuses on the relevance of using Internet and Information Technologies in teaching foreign languages. The author notes that employing IT will help to develop pupils' progress in multiple skills at the same time. Moreover, the author puts forward the assumption that lessons based on the Internet and IT can help to quickly master the skills of communication in the EFL compared to traditional face-to-face lessons.
\end{abstract}

KEY WORDS: Internet technologies, Information Technology (IT), Interactive technology, English as a foreign language (EFL), learning and teaching, school pupils.

\section{INTRODUCTION}

First of all, we will define the concept of "Internet technologies", which today is the most used in educational and methodological literature in comparison with other seemingly synonymous concepts: "Information technology", "Computer technology", "Interactive technology" and others. Internet technologies are a set of forms, methods, methods, techniques of teaching a foreign language using the resources of the Internet and their social services [5:12]. At the end of the $80 \mathrm{~s}$, a new independent direction of didactics and methods of teaching languages appeared - computational linguodidactics, which deals with theoretical issues of computerization of teaching in foreign languages.

There are a number of terms associated with the problem under consideration: database, information technology, computer technologies, Internet technologies, interactive mode, telecommunications, interface, distance learning, project methods. We have analyzed a number of scientific studies in the field of computerization of learning in foreign languages. As a result, they were able to get an idea of how computational linguodidactics developed, what problems of using the Internet were discussed by scientists from different countries. Early research articles of the 1980s were largely devoted to the issues of teaching pupils and students to work on a computer, the ability to work freely on a personal computer, and improve computer literacy [4: 39-44]. A large number of works in the $80 \mathrm{~s}$ and $90 \mathrm{~s}$ were devoted to the very phenomenon called computerization in the educational process, computer revolution, comprehended the importance, the need to use all these processes in learning [3:42-51]. In the late $80 \mathrm{~s}$, 90 s and early 2000s, the psychological and pedagogical problems of using computers in the educational process, the psychological consequences of computerization, the peculiarities of the mental states of computer users, taking into account their 
psycho-physiological, age and personal characteristics were actively discussed [1; 5:53-61].

The famous psychologist L.V. Vygotsky wrote: "The key to the whole problem of the psychological development of a teenager is the problem of interests in adolescence. All psychological functions of a person at each stage of development do not act haphazardly, not automatically and not accidentally, but in a certain system, guided by aspirations prevailing in adolescence, drives, interests" [8:64]. Interpersonal communication becomes the leading activity of a teenager. Cognitive activity and curiosity sharply increase in these schoolchildren. Interest in the surrounding world is growing. School interests give way to interests outside the school curriculum.

Most teenagers lose interest in learning English. If junior schoolchildren not only with interest, but also with pleasure begin to learn English - something unusual, new, easily assimilated for them, then many of them by the fifth grade are disappointed, lose interest in the language, in its study, since the volume of the material, the amount of information that a teenager must remember increases significantly according to the principle of a snowball, homework becomes more and more overwhelming, teachers get nervous (there is not enough time to go through the planned material in the lesson, the students do not learn anything), they begin to raise their voices to the students.

The cognitive processes of a pupil that are: perception, attention, imagination, memory, thinking, speech also undergo changes, and have their own characteristics in adolescence. Logical thinking develops. A teenager is able to analyze abstract ideas, easily abstract from concrete, visual material and reason, which leads to the development of speech in his native language. In a foreign language, a certain speech crisis sets in. Teenagers reject cramming, and cannot express their thoughts in words, since most of them have an extremely small stock of active vocabulary. The development of mechanical memory slows down, while logical memory is actively developing and gradually begins to dominate in memorizing linguistic and speech material. A teenager easily isolates and remembers semantic blocks of information and thus knows what he wants to say, but does not know (finds it difficult) how to say it in the target language. Contradictions are observed in the development of attention, its characteristics: the level of concentration, the volume of attention, its duration, and stability.

\section{METHODOLOGY}

First of all, we should consider the psychological and didactic aspects of the possibility of using Internet technologies in English lessons for $5^{\text {th }}-7^{\text {th }}$ grade students, and determine the place and role of the Internet in the lesson: why, at what stage of the lesson, in what volume it should be used. Main factors of attention are interest and motivation. However, since, as already have noted, interest in learning activity decreases, motivation decreases, fatigue increases, then attention, as "the process and state of tuning the subject to the perception of information" is violated. Attention becomes the chosen one. Thus, on a logically organized material, motivation increases, as a result, the volume of attention increases and can reach more semantic units. On the other hand, concentration, and hence the amount of attention, decreases if the teacher requires memorizing words that are not related in meaning, cramming text, dialogue. It should be remembered that the duration of attention is not unlimited. Even the most attentive student may be able to hold attention for no more than 10-15 minutes. What about the rest of the 30-35 minutes of the lesson? All of the above psychological characteristics and contradictions of adolescence lead to mental overload of the student, to stress, to his increased fatigue, to a decrease in his own selfesteem, which is important for a teenager. Motivation will fall rapidly. The original myth of the ease of learning English turns into an eternal myth about the impossibility of learning to speak English. How can this myth be dispelled? How and to whom to keep the active mental activity of a teenager in the classroom? How to make the process of language acquisition as efficient as possible? It depends on the participants in the educational process themselves. On the one hand, it depends on the student, and his desire to learn successfully, and his willpower. Also, this process depends on the teacher: according to his professional abilities, the level of English language proficiency, the quality of knowledge of the theory and methodology of teaching a foreign language, the knowledge and ability to creatively use modern technologies in the lessons of the studied language. In these conditions, it is Internet technologies that can save the situation, come to the aid of both students and teachers, as well as clearly demonstrate that the process of learning a language, its assimilation is entertaining, interesting and quite doable. In this regard, it remains to determine the role and place of Internet technologies in English lessons in grades 5-7.

The use of Internet technologies in the lessons of the target language is a need of the time. Of course, this is not a panacea for all problems, but it is simply unreasonable not to use the Internet in teaching today. The Internet contributes to the effective solution of a number of didactic tasks in the following:

1. When using Internet technologies, interest in the studied topic of the lesson instantly increases; 
2. Increased interest leads to instant concentration of attention, improved memory performance;

3. The thinking abilities of students are activated. Comprehension and assimilation of educational material becomes much more effective and stronger;

4. Even the most passive and weak pupils are involved in the educational process of the lesson.

5. The Internet provides real communication with native speakers, which greatly optimizes the learning process. In the lesson, not only the teacher reigns, but, albeit virtually, there is an Englishman or an American. And this is not necessarily a specialist in the field of teaching a foreign language. These can be the most ordinary people of different ages and professions, which can make the communication of students with them even more exciting. Students express their thoughts in English in real communication, which irrevocably increases motivation, the need for communication, and hence the need to learn English, awareness of its role as an intermediary language in contacts with native speakers, and not just to answer and get a good grade;

6. The Internet provides real communication for students not only with native speakers. Having arranged a teleconference, you can exchange information, discuss the topic under study, a joint project with students from other schools in Belgorod and the region, with students of the Faculty of Foreign Languages, which also increases motivation, the spirit of competition, the desire not to let down your class, your teacher, to be no worse, but even better than their peers in knowledge of the English language;

7. The Internet teaches students to work independently, raises its importance to the study of foreign language: it teaches to request information in the target language, exchange it, improves their skills independently and abilities in foreign language communication;

8. For the teacher, the use of Internet technologies in the classroom is also of great importance. Their application raises the authority of the teacher among students, their parents, among their colleagues.

\section{RESULTS AND DISCUSSION}

For teachers of foreign languages, and not only for students, there is an excellent opportunity to maintain and improve their knowledge of the language, their pronunciation, the ability to expand your stock of methodological techniques, technologies in the field of teaching foreign languages.

Unfortunately, some teachers neglect to use the Internet. Some believe that the lesson turns into "something entertaining" and interferes with the goals and objectives of the lesson. Others, recognizing the effectiveness of Internet technologies, are lazy to use them, since a lot of preparation is required: you need to find sites that pick up language and speech material, outline the stages of work on it, and foresee the situation if the Internet does not open in the lesson, therefore, this material must be recorded on a disk.

A modern teacher should remember one thing: the waste of time on preparation is nothing compared to the joy of learning, with the development of mental activity, with the development of initiative speech, with an increase in motivation to comprehend the language being studied, the desire to be able to communicate in this language. Teachers may not worry that computers and Internet technologies can completely replace them in the lesson, supplant them as an unnecessary element. No one replaces the teacher for the learners, the living immediate communication at the lesson, communication face-to-face. According to Chefranov: "I remember the first teacher and many of my university teachers with warmth and gratitude. Probably, this is correct when a teacher gives a start in life, and not Internet resources" [1].

Nevertheless, it is obvious that the use of Internet technologies is a reality of today. Therefore, the current teacher simply needs to keep up with the times, actively use Internet technologies, and master the existing Internet resources. It is much easier for an English teacher to do this, since on the Internet almost all information is presented in English, which, by the way, increases the importance of learning English compared to German, French and other foreign languages. There are many types of educational Internet resources. It is important for a teacher to know and learn how to properly use Internet resources in language learning. Modern Internet resources contain text, audio and visual material on various topics in different languages. For the convenience and productive use of resources in language learning, it became necessary to classify them. In modern English-language sources, five types of educational Internet resources are distinguished: hotlist, treasure hunt, multimedia scrapebook, subject sampler and webquest [6:42]. It should be noted that transliteration is used when translating these concepts into Karakalpak.

Internet technologies are something other than the use of the Internet in teaching a foreign language. The inclusion of Internet technologies in the educational process creates real opportunities to improve the quality of teaching foreign languages, including English. We assume that the leading remains the personality-activity approach, developed and substantiated by Winter [1999], according to which at the center of the educational process is, 
firstly, the personality - the student with his inherent individual psychological features and secondly, the activity-based nature of the approach means that the object of training should be a foreign language speech activity, its types. The features of this approach, its methodological content are the following factors:

1. The speech orientation of teaching assumes the focus of the teacher's attention on teaching communication, on the use of language for the purpose of exchanging thoughts, and the focus of the student's attention on the content of the statement, on its understanding and reproduction;

2. Speech-thinking activity as the constant involvement of students in the process of communication in a verbal or mental form;

3. The situational nature of the learning process as a way to stimulate speech activity and as a condition for improving communication skills;

4. The problematic nature of learning - the creation of problem situations in the classroom and discussion of possible approaches to their solution, which leads to the activation of the reserve capabilities of the individual, the activation of creative possibilities for students both at the stage of the introduction of the learned material, and at the stage of its consolidation in the process of assimilation;

5. Taking into account the individual psychological characteristics of students:

- the ability to master the language (memory, attention, phonemic hearing, logical thinking); - the ability to learn (how to learn words, how to understand the text, how to convey the main information in the text, how to improve listening mechanisms, how to write a letter to a friend); interests, worldview, position in the team; intellectual abilities (features of perception, thinking, imagination); - psyche (dynamics of mental activity, type of nervous system).

As we can see that it is the approach that makes it possible to introduce Internet technologies into the learning process, in view of the fact that it is they, in the light of this approach, that contribute to the effectiveness of the assimilation of a foreign language by students.

\section{CONCLUSION}

Thus, Attention is focused on the fact that the use of Internet technologies creates real opportunities to improve the quality of teaching English, as well as other foreign languages. One of the important conditions for this is a personal-activity approach to learning, the methodological support of which is represented by the speech orientation of learning, speech-thinking activity of students, the situational nature of the learning process and it is necessary to take into account the individual psychological characteristics of students in grades 57.

Based on these factors, the role and place of Internet technologies in English lessons in grades 5-7 were substantiated and the following conclusions have been made:

1. The use of Internet technologies today is a need of the time;

2. They contribute to the effective solution of a number of didactic tasks: - interest in the studied topic of the lesson increases; - concentration of attention increases; - memory performance improves; - the thinking abilities of students are activated; even the weakest and most passive students are involved in the lesson process; - real communication is provided with native speakers, as well as with their peers which ultimately unconditionally increases motivation, the need for communication, and therefore the need to learn English, awareness of its role as an intermediary language in contacts with native speakers;

3. The role of using the Internet in the classroom is determined not only for students, but also for the teacher of the foreign language;

4. The amount of time allowed for using the Internet in the lesson has been determined. The Internet use rate should not exceed 20 minutes of lesson time. Internet technologies, no matter how effective they are, cannot and should not completely replace the teacher in the classroom.

\section{REFERENCES}

1. Azimov E.G. Computer text editors at a foreign language lesson // Foreign languages at school. 1997. No. 1. pp. 54-57.

2. Briefly W., Kemble J.R. Computers as a tool in language teaching. Ellis Horwood Ltd., London, 1991. 231 p.

3. Kokkota V.A. Problems of computer implementation in teaching foreign languages // Communication issues in teaching foreign languages: Methodology. Tartu, 1986. pp. 4251 .

4. Masylko E.A. Problems of the organization of computer teaching of foreign language speech // Methods of teaching foreign languages: romance and Germanic education: republican interdepartmental collection. Minsk, 1987. pp. 39-44.

5. Prokhorov A.O., Serezhkina A.E. Features of mental states of computer users in the process of computerized learning // Questions of psychology. 1995. No. 3. pp. 53-61.

6. Sysoev P.V., Evstigneev M.N. Information and Communication Technologies in Education: Textbook. M.: Phoenix, 2015. 456 p.

7. Sarsenbaeva, Z.J., Utebaev, T.T. Role of phraseology in developing communicative competence. EPRA International Journal of Multidisciplinary Research (IJMR) - Peer 
Reviewed Journal Volume: 6 | Issue: 9. DOI: https://doi.org/10.36713/epra5111

8. Vygotsky L.S. Development of interests in transitional age // Collected works: In 6 volumes. Vol. 4. Children's psychology / Ed. D.B. Elkonin. M .: Pedagogika, 1984.432 p. 